\title{
Mensuração da capacidade do processo de beneficiamento de uva de mesa em um packing house: estudo de caso em uma empresa no Vale do São Francisco
}

\section{Measurement of table grape processing capacity in a packing house: case study in a company in San Francisco Valley}

\author{
Wendell Ramon Barbosa Machado Engenheiro de Produção. Universidade Federal do Vale do São Francisco (UNIVASF) - Brasil. \\ wendell_ramonsb@hotmail.com. \\ Pedro Vieira Souza Santos Mestre em Engenharia de Produção. Universidade Federal do Vale do São Francisco (UNIVASF) - \\ Brasil. pedrovieirass@hotmail.com.
}

\section{RESUMO}

O Vale do São Francisco é um dos principais polos produtores de frutas e hortaliças do país, possuindo diversas culturas de plantio. Nesse contexto, o estado de Pernambuco é um dos maiores produtor de uvas, assim como o Rio Grande do Sul. Logo, o objetivo dessa pesquisa foi medir a capacidade dos processos de beneficiamento da uva de mesa em uma empresa localizada no Vale do São Francisco, na cidade de Petrolina-PE. O estudo justificou-se pela necessidade de obter formas de controle de itens defeituosos para medição da capacidade de produção na etapa de beneficiamento da uva que acontece no packing house. Por meio de técnicas estatísticas foi obtida uma proporção média de itens defeituosos de 8,33\% nas avaliações feitas de outubro a dezembro de 2018. Desta forma, a empresa obteve um índice de capacidade de produção (C) de 91,17\% em conformidade. Com os resultados obtidos a empresa traçou uma meta anual e passou a utilizar o indicador de capacidade de processo como indicador gerencial de acompanhamento semanal com o intuito de garantir a qualidade de seus produtos a seus clientes e consumidores.

Palavras-chave: Agronegócio. Uva. Gestão.

\section{ABSTRACT}

The São Francisco Valley is one of the main fruit and vegetable producers in the country, with several planting cultures. In this context, the state of Pernambuco is one of the largest grape producers, as is Rio Grande do Sul. Therefore, the objective of this research was to measure the capacity of the table grape processing processes in a company located in the São Francisco Valley, in the city of Petrolina-PE. The study was justified by the need to obtain forms of control of defective items to measure the production capacity in the stage of grape processing that happens in the packing house. Through statistical techniques, an average proportion of defective items of $8.33 \%$ was obtained in the assessments made from October to December 2018. Thus, the company obtained a production capacity index (C) of $91.17 \%$ in conformity. With the results obtained, the company set an annual goal and started using the process capacity indicator as a management indicator for weekly monitoring in order to guarantee the quality of its products to its customers and consumers.

Keywords: Agribusiness. Grape. Management. 


\section{INTRODUÇÃO}

Com um grande destaque no cenário nacional, os estados da Bahia e de Pernambuco corresponderam em 2016 a 16,58\% da produção de Frutas do país. A Bahia possuía uma produção de frutas de 4.062 .515 toneladas, $2^{\text {a }}$ maior do país. $O$ estado de Pernambuco possuía em 2016 uma produção de 1.418 .541 toneladas, $7^{a}$ maior (KIST, 2018). Assim, o submédio do São Francisco, região a qual engloba esses dois estados, é conhecido como a região do Vale do São Francisco mais próspera na fruticultura, local que se encontra totalmente na zona semiárida do nordeste brasileiro. De acordo com Vidal e Ximenes (2016), a uva em Pernambuco corresponde a $38 \%$ do valor da produção do setor frutícola.

O Anuário Brasileiro de Fruticultura (2018) estima que, em 2016, a produção de uva no Brasil foi de 984.481 toneladas. Em 2015, Conforme Mello (2016), menos da metade da produção de uva foi voltado para o consumo in natura, sendo a maior parte voltado para produção de vinhos e sucos. Porém, em 2017, a produção destinada a consumi in natura foi de $51,26 \%$, superando o volume que é destinado a produção de vinhos e sucos (KIST, 2018). O consumo de uvas de mesa in natura possui dois destinos: o mercado nacional ou internacional. A literatura indica que, em média, $95 \%$ das exportações de uvas de mesa são provenientes da região do Vale do São Francisco.

Em 2015, o Anuário Brasileiro de Fruticultura apresentou um volume de exportação de uva em torno de 35 mil toneladas. Destaca-se as variedades sem sementes, que conquistaram o mercado internacional, devido ao sabor e qualidade (KIST, 2017). Da saída do campo até as gôndolas dos mercados do Brasil e do mundo, a uva possui uma cadeia produtiva pós-colheita. Essa atividade de beneficiamento inicia-se no campo e termina no packing house (casa de embalagem). Desta forma, visando manter a qualidade do produto, o controle dos processos referentes ao beneficiamento desta fruta tem um papel fundamental. De acordo com Oro (2010), um processo de produção sob controle estatístico, qualquer variação que não seja inerente ao processo, poderá ser identificada e eliminada.

De acordo com Vieira (2014) e Prata e Santos (2020), o conceito de qualidade possui diferentes interpretações. Juran (1989) conceitua qualidade como adequação ao uso. Santos e Silva (2019) reforçam a afirmativa de Crosby (1990), que cita que a qualidade é a conformidade do produto as suas especificações. Por último, a ISO 9000 (ASSOCIAÇÃO BRASILEIRA DE NORMAS TÉCNICAS, 2015) afirma que a qualidade de qualquer produto pode ser determinada pela comparação de um conjunto de características que lhe são intrínsecas com um conjunto de especificações. Por fim, de acordo com a ISO 8402 (ASSOCIAÇÃO BRASILEIRA DE NORMAS TÉCNICAS, 1997) o termo qualidade é definido como "[...] a totalidade de características de uma entidade que lhe confere a capacidade de satisfazer as necessidades explícitas e implícitas [...]".

Para a ISO 8402 (ASSOCIAÇÃO BRASILEIRA DE NORMAS TÉCNICAS, 1997) a gestão da qualidade inclui "[...] o controle da qualidade e a garantia da qualidade, bem como, os conceitos de políticas da qualidade, planejamento da qualidade e melhoria da qualidade. A gestão da qualidade abrange todo o sistema da qualidade [...]". Essa norma afirma que o controle da qualidade compreende técnicas operacionais destinadas ao monitoramento de um processo.

Para o monitoramento do processo, Vieira (2014) afirma que: "Todo fabricante quer produzir dentro dos limites de especificação [...] e itens produzidos fora da especificação constituem perdas." Ainda segundo o autor, um sistema produtivo é classificado como "capaz" se estiver produzindo itens com medidas dentro das especificações definidas (VIEIRA, 2014). Assim, o gerenciamento da qualidade busca controlar as atividades da organização para alcançar a qualidade almejada, atendendo às condições esperadas pelos clientes (CARVALHO; PALADINI, 2012; SANTOS, 2019). Além disso, as especificações atendidas por produtos de qualidade são consideradas primordiais na sustentabilidade do negócio e na manutenção das atividades da empresa no mercado, conforme apontam Mota et al. (2019).

O presente estudo foi realizado em uma empresa de produção e beneficiamento de uvas de mesa, organização de médio porte atuante em níveis nacional e mundial, com presença no Reino Unido, Alemanha, Bélgica, Holanda, Suécia, Suíça, Estados Unidos e em 16 estados brasileiros. A empresa está localizada na cidade de Petrolina - PE. Tal organização nunca fez um estudo sobre o controle de itens defeituosos para medição de sua capacidade de produção na etapa de beneficiamento da uva que acontece no packing house. 
Assim, foi de fundamental importância a consumação desse estudo, tendo em vista que o acompanhamento da qualidade do produto acabado faz com que a empresa tenha segurança e garantia que os produtos enviados para os mais de 100 clientes nacionais e internacionais estejam em conformidade. Sendo assim, o objetivo dessa pesquisa foi medir a capacidade dos processos de beneficiamento da uva de mesa em uma empresa localizada no Vale do São Francisco, na cidade de Petrolina-PE.

\section{ABORDAGEM TEÓRICA}

Nessa seção serão abordados os principais tópicos que embasam o estudo, do ponto de vista teórico. Nela, são apresentados os conceitos intrínsecos ao setor do agronegócio com foco na produção de uva, aspectos da região do Vale do São Francisco e ainda definições sobre o método de controle estatístico do processo.

\subsection{Vale do São Francisco}

A região do Vale do Rio São Francisco compreende uma área de 64 milhões de hectares (ha), dividida em 04 (quatro) regiões, sendo elas: Alto São Francisco, Médio São Francisco, Submédio São Francisco-e Baixo São Francisco (BUAINAIN; BATALHA, 2007). Na figura 1 é exibido o mapa com a divisão das 04 (quatro) regiões:

Figura 1 - Mapa do Vale do são Francisco.

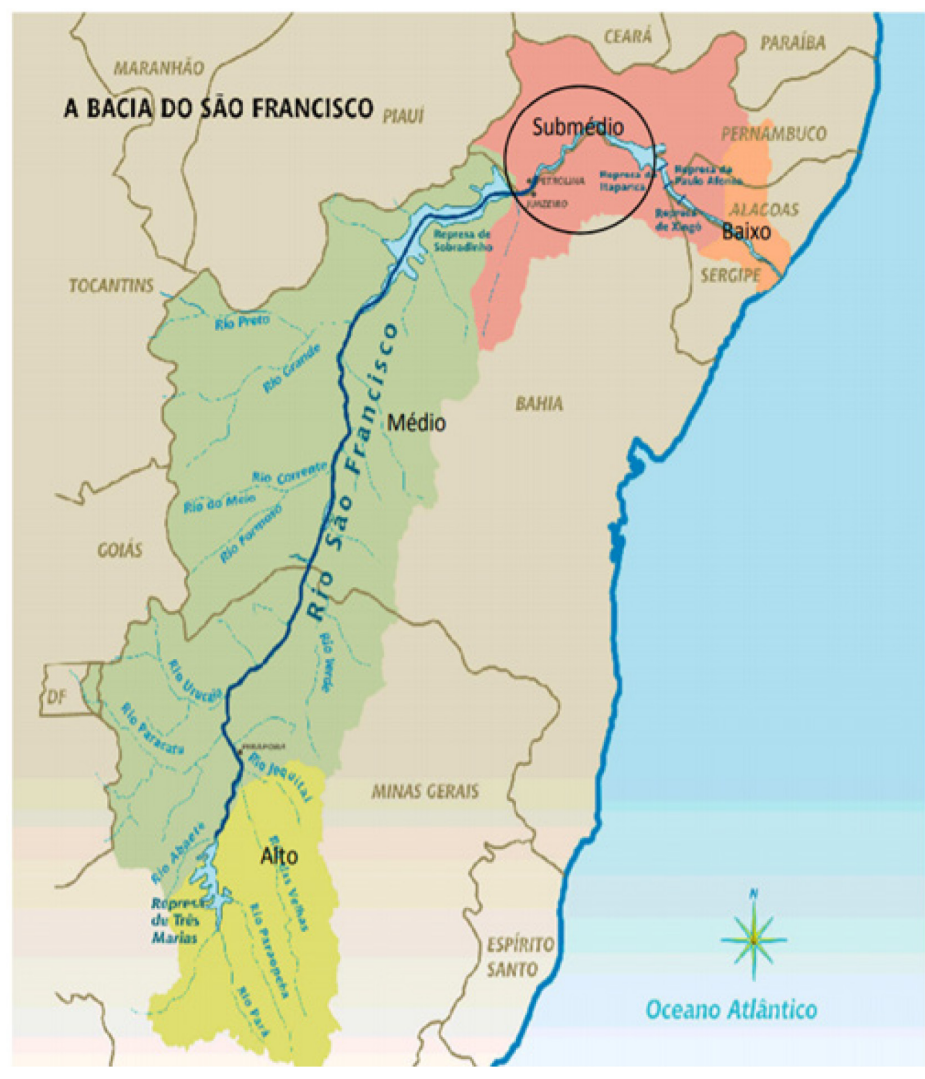

Fonte: DOMINGUES (2015).

O Nordeste consta no ranking das principais regiões brasileiras produtoras de alimentos, derivados da transformação primária de frutas e hortaliças. Dada a sua vocação para produção de frutas e hortaliças, a agroindústria de alimentos proveniente dessas matérias-primas está localizada nos principais polos de concentração da agricultura irrigada e de sequeiro na maioria dos estados nordestinos (BRAINER et al., 2008; SANTOS, 2020). 
O Vale do São Francisco, aí localizado, abrange grande parte dos estados de Pernambuco e da Bahia. Suas vinícolas produzem diversos tipos de vinhos finos tintos, brancos e espumantes, chamados de "vinhos tropicais" devido às características do clima tropical semiárido e suas particularidades que o tornam um diferencial para o setor (SANTOS, 2017, p. 57).

Logo, como uma das principais culturas cultivadas, a uva produzida no vale possui 02 (duas) finalidades principais: consumo in natura (uva de mesa) ou produção de vinhos/sucos. Em 2016, a produção brasileira de frutas frescas foi cerca de 38,7 milhões de toneladas, dos quais 984.481 toneladas de quilos correspondem à uva (KIST, 2018).

\subsection{Característica da Uva de Mesa}

Devido às condições do clima, solo e dos tratos culturais pode-se colher uva durante todo o ano no Vale do São Francisco. Leão (2004) relata os tratos culturais que são feitos nas videiras, sendo necessários para obtenção de uma produção de alta qualidade. Os tratos seguem uma sequência. Essas etapas possuem uma sequência lógica que acompanham as fases fenológicas da planta cultivada.

O sistema de produção de uva de mesa é complexo e compactuam de 02 (dois) principais grupos: précolheita e pós-colheita (LEÃO et al., 2004). Segue o quadro 1 descrevendo as principais etapas da cadeia produtiva.

Quadro 1 - Cadeia Produtiva da Uva de Mesa

\begin{tabular}{|c|c|}
\hline \multicolumn{2}{|r|}{ PRÉ-COLHEITA } \\
\hline ETAPAS & DESCRIÇÃO \\
\hline Localização & Solos com profundidade média de 1,5 m e bem drenados. \\
\hline Limpeza da área & Fazer roçagem e destocamento de 3 a 4 meses antes do plantio. \\
\hline Análise de solo & Logo após a limpeza da área, coletar amostras de solo para análise. \\
\hline $\begin{array}{l}\text { Calagem } \quad \text { e/ou } \\
\text { Gessagem }\end{array}$ & Se houver necessidade, fazê-las pelo menos 60 dias antes do plantio. \\
\hline Adubação & Antes do plantio, colocar a matéria orgânica e os nutrientes minerais de acordo com a análise do solo. \\
\hline $\begin{array}{l}\text { Adubação de Cobertura } \\
\text { na Fase de Produção }\end{array}$ & Incorporar matéria orgânica nos sulcos ou covas, durante o repouso, e os minerais via água de irrigação \\
\hline A Escolha da Variedade & Depende da finalidade: se para mesa, passas, sucos ou vinhos. \\
\hline Produção de Mudas & $\begin{array}{l}\text { As plantas selecionadas para fornecerem as estacas para produção de mudas devem ter crescimento } \\
\text { vigoroso, alta produtividade, bom aspecto sanitário, ramos bem lignificados e bem formado. }\end{array}$ \\
\hline Sistema de Condução & $\begin{array}{l}\text { O mais empregado para uvas de mesa é a latada. Outros sistemas estão sendo testados para uvas sem } \\
\text { sementes. }\end{array}$ \\
\hline Plantio & $\begin{array}{l}\text { Pode ser efetuado em qualquer época do ano, podendo o espaçamento variar entre } 3 \times 2 \mathrm{~m} \text { e } 4 \times 3 \mathrm{~m} \text {. Antes } \\
\text { ou imediatamente após plantar a muda, enterrar um tutor que conduzirá a brotação verticalmente até o } \\
\text { arame do sistema de condução. }\end{array}$ \\
\hline $\begin{array}{l}\text { Poda de condução e } \\
\text { amarração }\end{array}$ & $\begin{array}{l}\text { Após o plantio, conserva-se um único ramo, que é conduzido até a latada, amarrado ao tutor, para dar } \\
\text { origem a uma planta com o tronco bem ereto e evitar que se quebre pela ação do vento. Os ramos ladrões } \\
\text { que saem do porta enxerto e as brotações laterais são eliminados ainda novos. Quando o ramo atingir a } \\
\text { latada deve ser conduzido com um ou dois braços primários no sentido da linha de plantio. }\end{array}$ \\
\hline Limpeza & $\begin{array}{l}\text { Evitar a competição com as ervas invasoras através de roça manual ou mecanizada. Uso de cobertura morta } \\
\text { ou adubo verde favorece as condições do solo e a disponibilidade de nutrientes reduzindo a incidência de } \\
\text { ervas invasoras. }\end{array}$ \\
\hline $\begin{array}{l}\text { Tratamentos } \\
\text { Fitossanitários }\end{array}$ & $\begin{array}{l}\text { Fazer monitoramento e controle das pragas e doenças quando necessário. Principais doenças: míldio, } \\
\text { oídio, cancro bacteriano, antracnose, morte descendente. Principais pragas: ácaros branco e rajado, tripes, } \\
\text { cochonilha, mosca branca e broca dos ramos. }\end{array}$ \\
\hline Irrigação & $\begin{array}{l}\text { Deve ser realizada a cada sete dias em solos pesados e a cada quatro dias em solos leves até o pegamento } \\
\text { das mudas. Com plantas bem desenvolvidas irrigar quando o solo atingir } 50 \% \text { de umidade disponível no } \\
\text { perfil até } 100 \mathrm{~cm} \text {. }\end{array}$ \\
\hline Podas de Produção & $\begin{array}{l}\text { Podem ser mistas, com varas de } 7 \text { a } 15 \text { gemas e esporões ( } 2 \text { a } 3 \text { gemas); curtas, apenas com esporões, } \\
\text { usadas para renovação da copa, ou longas, com varas para a produção concentrada em uma safra anual. }\end{array}$ \\
\hline
\end{tabular}




\begin{tabular}{|c|c|}
\hline Poda Verde & $\begin{array}{l}\text { Desbrota para eliminar o excesso de brotações, retirando aquelas que não tem cacho e estão fracas, duplas, } \\
\text { mal formadas ou mal posicionadas. }\end{array}$ \\
\hline $\begin{array}{l}\text { Desnetamento } \\
\text { desgavinha }\end{array}$ & Para eliminar o excesso de netos (feminelas ou brotos terciários) e gavinhas. \\
\hline Desbaste dos cachos & Para eliminar os cachos dos ramos mais fracos, com poucas folhas ou sob excesso de ramos e folhas. \\
\hline $\begin{array}{ll}\text { Descompactação ou } \\
\text { Raleio dos Cachos }\end{array}$ & $\begin{array}{l}\text { Pode ser realizado em três fases: pré-floração (com pente ou manualmente); em fase de "chumbinho" } \\
\text { (manualmente, "pinicado") e em "ervilha" (com tesoura). }\end{array}$ \\
\hline $\begin{array}{l}\text { Reguladores } \\
\text { Crescimento }\end{array}$ & $\begin{array}{l}\text { Cianamida hidrogenada ( } 5 \text { a } 7 \% \text { ) aplicada imediatamente após a poda para uniformizar e adiantar a } \\
\text { brotação; ácido giberélico, usado para alongamento do engaço e aumentar tamanho de bagas e Ethephon } \\
\text { na fase de mudança de cor em variedades vermelhas, para uniformizar a coloração. }\end{array}$ \\
\hline $\begin{array}{l}\text { Colheita } \text { Colher as uvas } \\
\text { quando } \quad \text { estiverem } \\
\text { maduras. }\end{array}$ & $\begin{array}{l}\text { A maturação pode ser determinada medindo o teor de sólidos solúveis totais, pelo amolecimento da baga } \\
\text { ou pelo tempo contado a partir da brotação. Utilizar contentores limpos e sanitizados, forrados com } \\
\text { material macio, flexível e lavável, colocar os contentores ao longo da linha de plantio, em posição inclinada, } \\
\text { apoiados no caule das plantas. }\end{array}$ \\
\hline \multicolumn{2}{|r|}{ PÓS-COLHEITA } \\
\hline ETAPAS & DESCRIÇÃO \\
\hline $\begin{array}{l}\text { Transporte para a } \\
\text { empacotadora }\end{array}$ & $\begin{array}{l}\text { Retirar os contentores cuidadosamente da área do parreiral; realizar o transporte em baixa velocidade por } \\
\text { vias regulares, internas da propriedade; receber os frutos colhidos na empacotadora no mesmo dia. }\end{array}$ \\
\hline Limpeza dos cachos & $\begin{array}{l}\text { Realizar a limpeza dos cachos retirando frutos estragados, imaturos, podres, roídos por animais, } \\
\text { pedúnculos sem bagas etc. }\end{array}$ \\
\hline Classificação & $\begin{array}{l}\text { Classificar os cachos de acordo com o Regulamento Técnico de Identidade e de Qualidade para a } \\
\text { Classificação de Uva de Mesa para Exportação. }\end{array}$ \\
\hline Beneficiamento & $\begin{array}{l}\text { Utilizar embalagens resistentes ao transporte e armazenamento que não promovam danos à fruta; colocar } \\
\text { na embalagem apenas frutos da mesma variedade e qualidade e homogêneas quanto ao tamanho; } \\
\text { identificar na caixa de embalagem, variedade, peso, produtor, parcela ou lote etc. para fins de } \\
\text { rastreabilidade. Antes de fechar a embalagem colocar o"sachet" de metabissulfito fase lenta para proteção } \\
\text { dos frutos contra podridões. Agrupar as embalagens em paletes de madeira. }\end{array}$ \\
\hline Pré-resfriamento & $\begin{array}{l}\text { Realizar o pré-resfriamento para uvas destinadas ao armazenamento em túnel de ar forçado de modo a } \\
\text { reduzir a temperatura do fruto para } 0^{\circ} \mathrm{C} \text {. }\end{array}$ \\
\hline Armazenamento & Armazenar os paletes em câmara refrigerada em temperatura de 1 a $2^{\circ} \mathrm{C}$ e $95 \%$ de umidade relativa. \\
\hline
\end{tabular}

Fonte: Leão et al. (2004, p. 13)

Como exibido no quadro acima, as etapas de pré-colheita possuem um foco na parte agronômica, pois são nessas etapas que estão todos os preparos do solo e da planta para que a fruta tenha todos os aspectos de qualidade necessários para o consumo. Por outro lado, as atividades de pós-colheita possuem um foco diferente, pois devem ser executadas o mais rápido possível para que a fruta possa conservar seus principais atributos.

A diminuição do frescor e risco de contaminação são problemas que as etapas da pós-colheita procuram evitar. Como as frutas são tecidos vivos, nos quais acontecem diversas reações bioquímicas, sendo que algumas podem levar rapidamente à senescência do vegetal comprometendo o frescor. Por sua vez, a contaminação compromete a segurança do alimento, bem como a qualidade final do produto, uma vez que o crescimento microbiológico pode levar a sérias alterações como o aparecimento de odores e sabores indesejáveis (CENCl, 2011).

\subsubsection{Aspectos de Qualidade da Uva de Mesa}

A qualidade é o conjunto de atributos que determinam o grau de aceitação do produto pelo consumidor final. A importância da qualidade do produto está diretamente ligada ao atendimento das expectativas do cliente. Os produtos podem ter atributos diferentes dependendo da finalidade de uso, como a uva de mesa para o consumo in natura e a uva para a produção de suco. Os atributos de qualidade são evolutivos, mudam com o tempo (LUENGO; CALBO, 2006.

Mascarenhas et. al (2013) relata alguns aspectos de qualidade sensorial e físico-química da uva de mesa, sendo eles: tonalidade de cor principal; uniformidade de cor principal; aroma característico; firmeza; doce; amargo; ácido; adstringência e sabor. O quadro 2 contém a descrição de cada aspecto citado. 
Quadro 1 - Aspectos de qualidade sensorial e físico-química da uva de mesa

\begin{tabular}{|c|c|}
\hline ASPECTOS DE QUALIDADE & CÃO \\
\hline $\begin{array}{l}\text { 1. Tonalidade de Cor } \\
\text { Principal (fraca-forte) }\end{array}$ & $\begin{array}{l}\text { Relativa à principal cor externa da baga, refere-se à dimensão da sensação visual da cor, } \\
\text { correlacionada ao comprimento de onda dominante da luz que incide nos receptores visuais. }\end{array}$ \\
\hline $\begin{array}{l}\text { 2. Uniformidade de Cor } \\
\text { Principal (baixa-alta) }\end{array}$ & $\begin{array}{l}\text { Relativa à parte externa da baga, refere-se à intensidade de variação dos raios luminosos que } \\
\text { estimulam a retina, com comprimentos de ondas dentro do espectro visível. }\end{array}$ \\
\hline $\begin{array}{l}\text { 3. Aroma Característico (fraco } \\
\text { - forte) }\end{array}$ & Ifativ \\
\hline 4. Firmeza (menos - mais) & formação, através da compressão \\
\hline 5. Doce (menos - mais) & sto primário produzido por soluções aquosas de várias substâncias, tipo açúcar sacarose. \\
\hline 6. Amargo (menos - mais) & nário produzido por soluções aquosas da maioria das substâncias ácidas, tipo quinina e \\
\hline 7. Ácido (menos - mais) & po ácido cítrico. \\
\hline $\begin{array}{l}\text { 8. Adstringência (menos } \\
\text { mais) }\end{array}$ & $\begin{array}{l}\text { Propriedade sensorial de substâncias puras ou misturas que produzem a sensação adstringente, } \\
\text { resultante da contração da mucosa da boca; exemplo: tanino de caqui ou banana verde. }\end{array}$ \\
\hline $\begin{array}{l}\text { 9. Sabor (menos saboroso } \\
\text { mais saboroso) }\end{array}$ & $\begin{array}{l}\text { Concernente ao aroma e sabor, refere-se especificamente à experiência mista, mas unitár } \\
\text { sensação gustativa e trigemial percebida durante a degustação e denominada de sabor. }\end{array}$ \\
\hline
\end{tabular}
Fonte: Mascarenhas et. al (2013, p. 550)

Entretanto, os aspectos de qualidade citados acima, não corroboram com os aspectos de qualidade que caracterizam o processo de beneficiamento de uva no packing house. Por outro lado, para que a uva embalada atinja os padrões de qualidade deve haver as seguintes etapas: limpeza, classificação e embalagem (CHOUDHURY et al., 2001). Ainda de acordo com eles, realiza-se a limpeza dos cachos segurando-os particularmente pelo pedúnculo e removendo, com tesoura apropriada, as bagas muito verdes, pequenas e defeituosas. Em seguida, os cachos são classificados conforme a coloração, tamanho de bagas, peso de cachos e ocorrência de defeitos.

\subsection{Controle estatístico da qualidade}

Nas atividades agrícolas, a gestão da qualidade traz aumento da produtividade e redução de custos; aumento da qualidade dos produtos agrícolas; efetivação do desenvolvimento sustentável e melhoria da qualidade de vida do trabalhador rural e agroindustrial. Para alcançar as melhorias que a gestão da qualidade se propõe, Vieira (2014) cita as "07 (sete) ferramentas estatísticas da qualidade": Folha de Verificação, Fluxograma, Diagrama de Pareto, Histograma, Diagrama de Dispersão, Diagrama de Causa Efeito e Gráfico de Controle de Processos ou de Shewhart.

As oscilações e variações que acontecem no sistema produtivo fazem com que ele seja monitorado permanentemente a fim de identificar desvio das especificações e variabilidade excessiva em torno das especificações. Graeml e Peinado (2007) afirmam que antes de se iniciar uma carta de controle estatístico é necessário definir o tipo de grandeza que se pretende controlar, sendo elas do tipo variável ou do tipo atributo, pois cada uma possui seus gráficos de controle.

As variáveis são características de qualidade que são mensuráveis, como, por exemplo: o diâmetro de um rolamento, uma resistência elétrica, o peso de uma caixa entre outros. Por seu turno, os atributos são características que são comparadas com especificações estabelecidas e, por isso, podem assumir apenas valores discretos (classificação conforme ou não conforme e contagem de defeitos) (RIBEIRO; TEN CATEN, 2012).

Após alcançar a meta do controle estatístico (produzir dentro dos limites de controle) e eliminar todas as causas especiais que causam inferência no processo, deve-se medir a capacidade do processo de produzir itens dentro dos limites de especificação dos clientes. Não existe qualquer relação matemática ou estatística entre limites de especificação (estabelecidos no projeto) e limites de controle (calculados com dados do processo em andamento) (VIEIRA, 2014).

No caso dos atributos, a capacidade é expressa, em geral, como o percentual (\%) de produtos conformes que o processo é capaz de produzir. Essa capacidade deve ser comparada com as expectativas e metas gerenciais. Caso ela não seja satisfatória, a gerência deve agir sobre o sistema (causas comuns) (RIBEIRO; 
TEN CATEN, 2012), podendo ainda utilizar sistemas de ERP para registro e análise de dados (ARAUJO et al., 2019).

\subsubsection{Gráficos de controle por atributos}

Existem vários tipos de gráficos de controle de atributos e todos têm indicação precisa. O gráfico de controle $n p$ monitora o número de itens não conformes em amostras de tamanho constante, por outro lado, o gráfico de controle $p$ monitora a proporção de itens não conformes em amostras de tamanho constante ou variável. Além disso, têm-se o gráfico de controle $c$ que monitora o número de não conformidades em unidades de tamanho constante e, por fim, o gráfico de controle $u$ que monitora o número médio de não conformidades em unidades de tamanho constante ou variável (VIEIRA, 2014).

Em um estudo sobre avaliação de um processo da irrigação localizada, utilizando cartas de controle, Andrade (2016), concluiu que em relação à microaspersão (uma das diversas formas de irrigar plantações), os menores espaçamentos apresentaram as maiores uniformidades de distribuição e o uso de um sistema de armazenamento de energia quando utilizada a energia solar fotovoltaica para bombeamento de água diminui as variabilidades da uniformidade.

Em outro estudo, Costa (2017) relata sobre os pontos críticos na produção de medicamentos em uma indústria farmacêutica a partir da aplicação das cartas de controle para diferentes elementos, foi medido a capacidade do processo de diferentes elementos. Identificou-se no experimento que, para os parâmetros peso líquido e peso do talco o processo se caracterizou como não capaz. Por outro lado, para o peso líquido do gás e para a pressão, o processo se caracterizou como razoavelmente capaz e capaz, respectivamente.

\subsubsection{Carta de controle $\boldsymbol{p}$}

A NBR 5426 afirma que a inspeção por atributo correspondente a unidade de produto é classificada como defeituosa ou não (ou o número de defeitos é contado) em relação a um dado requisito ou conjunto de requisitos (ASSOCIAÇÃO BRASILEIRA DE NORMAS TÉCNICAS, 1985). Para melhorar a produtividade e a lucratividade da empresa, a aplicação desses diversos gráficos para o monitoramento dos processos industriais e administrativos é de extrema importância. Embora a prática da mensuração de características seja sempre melhor em termos científicos, têm razões para evitar a mensuração de algumas características do processo, concentrando apenas na contagem de peças não conformes ou no número de defeitos na peça (SAMOHYL, 2009).

Para construir o gráfico de controle $p$ deve-se identificar se a amostra possui tamanho fixo ou variável. Segue formulações para a construção de gráficos de controle $p$ e de limites de controle para cada amostra, no caso de amostras de tamanhos diversos (VIEIRA, 2014).

- A média das proporções $(\bar{p})$ de itens não conformes nas m amostras é expresso pela equação 1:

$$
\bar{p}=\frac{\sum d_{i}}{\sum n_{i}} i=1,2,3, \ldots, m(1)
$$

- $\quad$ O desvio padrão para cada amostra é dada pela fórmula 2:

$$
s_{i}=\sqrt{\frac{\overline{p(1-\bar{p})}}{n_{i}}} \quad i=1,2,3, \ldots, m
$$

- O limite superior de controle $\left(L S C_{i}\right)$ e limite inferior de controle $\left(L I C_{i}\right)$ para cada amostra é dado pela expressão matemática 3 e 4, respectivamente: 


$$
\begin{aligned}
& L S C_{i}=\bar{p}+3 \sqrt{\frac{\bar{p}(1-\bar{p})}{n_{i}}} \\
& L I C_{i}=\bar{p}-3 \sqrt{\frac{\bar{p}(1-\bar{p})}{n_{i}}}
\end{aligned}
$$

Quando os dados exibem mais variações do que se esperaria com base em uma distribuição binomial (para unidades defeituosas) existe uma superdispersão. Cartas $\mathrm{P}$ tradicionais admitem que sua taxa de unidades defeituosas permanece constante ao longo do tempo.

Não obstante, fatores de ruídos externos, que não são causas especiais, normalmente causam alguma variação na taxa de unidades defeituosas ao longo do tempo. Quando os subgrupos são grandes o suficiente a superdispersão pode fazer com que pontos pareçam estar fora de controle quando eles não estão. Sendo assim, para que se tenha um processo de avaliação correto, indica-se a utilização de carta de controle, Carta $P$ de Laney (PEREIRA NETO, 2018).

\subsubsection{Capacidade do processo}

Conforme Ribeiro, Ten Caten (2012) a capacidade do processo no caso de avaliação por atributo pode ser medida conforme equação 5 .

$$
C=1-\bar{p}
$$

Onde, $C$ é capacidade de produção de itens não defeituosos e $\bar{p}$ é a proporção média de itens defeituosos.

\section{METODOLOGIA}

Para a seguinte pesquisa, o procedimento metodológico foi elaborado com dois tipos, sendo elas: pesquisa descritiva e exploratória. Cervo et al. (2007, p. 61) propõem que "[...] a pesquisa descritiva observa, registra, analisa e correlaciona fatos ou fenômenos (variáveis) sem manipulá-los [...]". Corroborando, Gil (2008) afirma que a pesquisa descritiva possui como objetivo a descrição das características de uma população, fenômeno ou de uma experiência.

Conforme descrito anteriormente, o estudo também possui um caráter exploratório. Estudos exploratórios são todos aqueles que buscam descobrir percepções de ideias na tentativa de adquirir maior familiaridade com o fenômeno pesquisado. Os estudos exploratórios permitem ampliar a noção do pesquisador sobre os fatos, admitindo a formulação mais precisa de problemas (SELLTIZ et al., 1965; OLIVEIRA, 2011).

Além disso, Gil (2008) afirma que a maior parte das pesquisas exploratórias abrangem o levantamento bibliográfico, entrevistas com pessoas que têm conhecimentos práticos a respeito do problema investigado e análise de exemplos que estimulem a captação. Essas pesquisas podem ser classificadas como: pesquisa bibliográfica e estudo de caso. Complementando, o objetivo de uma pesquisa exploratória é familiarizar-se com um assunto ainda pouco conhecido, pouco explorado.

Desta forma, o estudo exploratório é recomendado em casos de limitações nos conhecimentos sobre determinado assunto, característica dessa pesquisa no que tange à utilização de cartas de controle por atributo no processo de beneficiamento de uva.

A pesquisa foi construída conforme a Figura 2, seguindo as etapas nela descrita. 
Figura 2 - Etapas da pesquisa

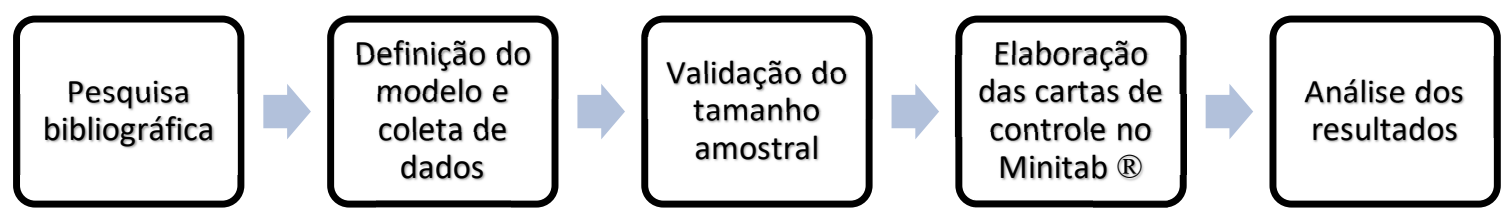

Fonte: Elaborado pelos autores (2020)

O estudo foi realizado em uma empresa localizada na cidade de Petrolina-PE, município inserido no Vale do São Francisco. A empresa possui mais de 20 anos na produção e beneficiamento de uvas de mesa e possui uma área plantada de mais de 300 hectares exclusivamente com uvas de mesa.

A coleta de dados se deu no período de maior produção, do dia 05/10/2018 a 28/12/2018, período no qual existe uma boa rentabilidade de exportar uvas para Europa e Estados Unidos. Neste período, a capacidade instalada de beneficiamento no packing house é de $80 \mathrm{mil} \mathrm{kg} \mathrm{de} \mathrm{uva} \mathrm{por} \mathrm{dia.} \mathrm{As} \mathrm{avaliações} \mathrm{de} \mathrm{qualidade} \mathrm{são}$ feitas pela equipe de Auditoria de Qualidade da empresa, esse setor é inteiramente independente do setor produtivo para a garantia da qualidade e confiabilidade dos dados.

A equipe de inspetores da qualidade possui um checklist no qual são inspecionados 15 itens e a combinação de ambos caracterizam se o produto é defeituoso ou não. Neste formulário, existem dois grupos a serem avaliados, sendo eles: qualidade e condição da uva. Dessa forma, a classificação do item em defeituoso ou não, está relacionado a aspectos como presença de podridão, cicatrizes, pragas e bagas imaturas.

\subsection{Validação do tamanho amostral}

Para identificação do tamanho amostral, inicialmente, considerou-se a produção real de unidades de caixa do período de outubro a dezembro de 2018. Desse modo, o tamanho amostral foi determinado e os dados foram coletados mediante checklist da avaliação da qualidade do produto na linha de produção. Considerou-se para este estudo um intervalo de confiança de $95 \%$ e margem de erro mínima de $\pm 5 \%$. Segundo Barbetta (2004) quando se reconhece o tamanho da população é possível avaliar a dimensão da amostra através das equações baixo:

$$
n_{0}=\frac{1}{E_{0}^{2}}(6) \quad n=\frac{n_{0} \cdot N}{n_{0}+N}(7)
$$

Onde $N$ é o tamanho da amostra (número de elementos) da população, $n$ é o tamanho (número de elementos) da amostra, $n_{0}$ é uma primeira aproximação para o tamanho da amostra e $E_{0}$ corresponde ao erro amostral tolerável pela pesquisa.

Após o cálculo conforme indicado acima, com uma produção neste período de 749.307 caixas de 5 kg, identificou-se uma amostra necessária de mínimo de 400 itens (que correspondem a caixas de $5 \mathrm{~kg}$ ) a serem avaliados para que se tenha garantia e confiabilidade dos dados. O número amostrado foi de 21.224 caixas, sendo muito superior à necessidade mínima do experimento.

\section{RESULTADOS E DISCUSSÕES}

A primeira análise foi feita com base na carta de controle do tipo $\mathrm{P}$ tradicional, porém, o Minitab ${ }^{\circledR}$ alerta sobre o risco de ter superdispersão e indica a utilização da carta P Laney. Para confirmação, na Figura 3 é exibido uma variação de 356,32\%, reafirmando a utilização da carta P de Laney. Com isso, foi constatado que o processo estava sobre controle e não tinha ação sobre ele nenhuma causa especial. 
Figura 3 - Relatório de diagnóstico da carta a ser utilizada

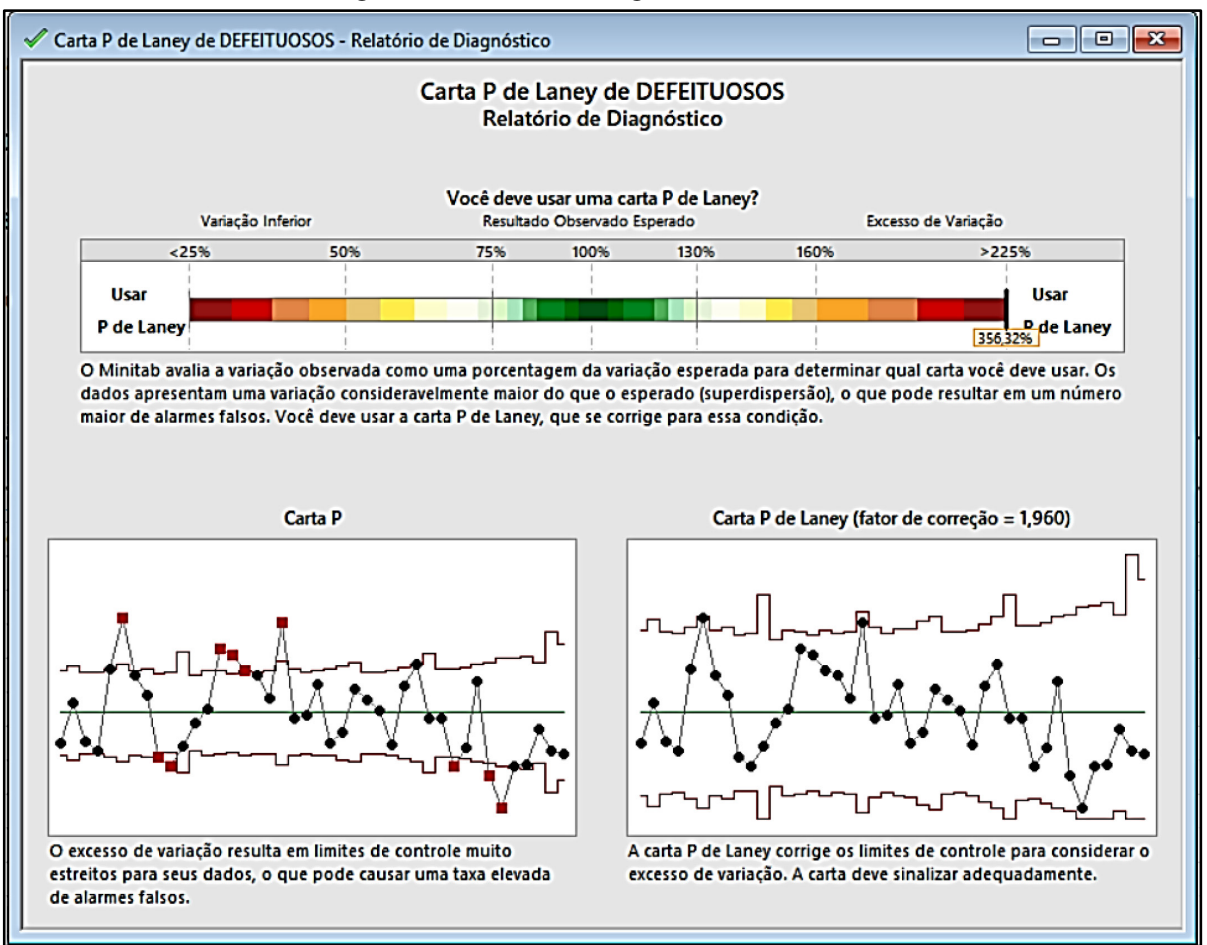

Fonte: Autores.

Para validar a amostra utilizada, na Figura 4 é exibido o relatório técnico do Minitab ${ }^{\circledR}$ sobre os dados amostrados.

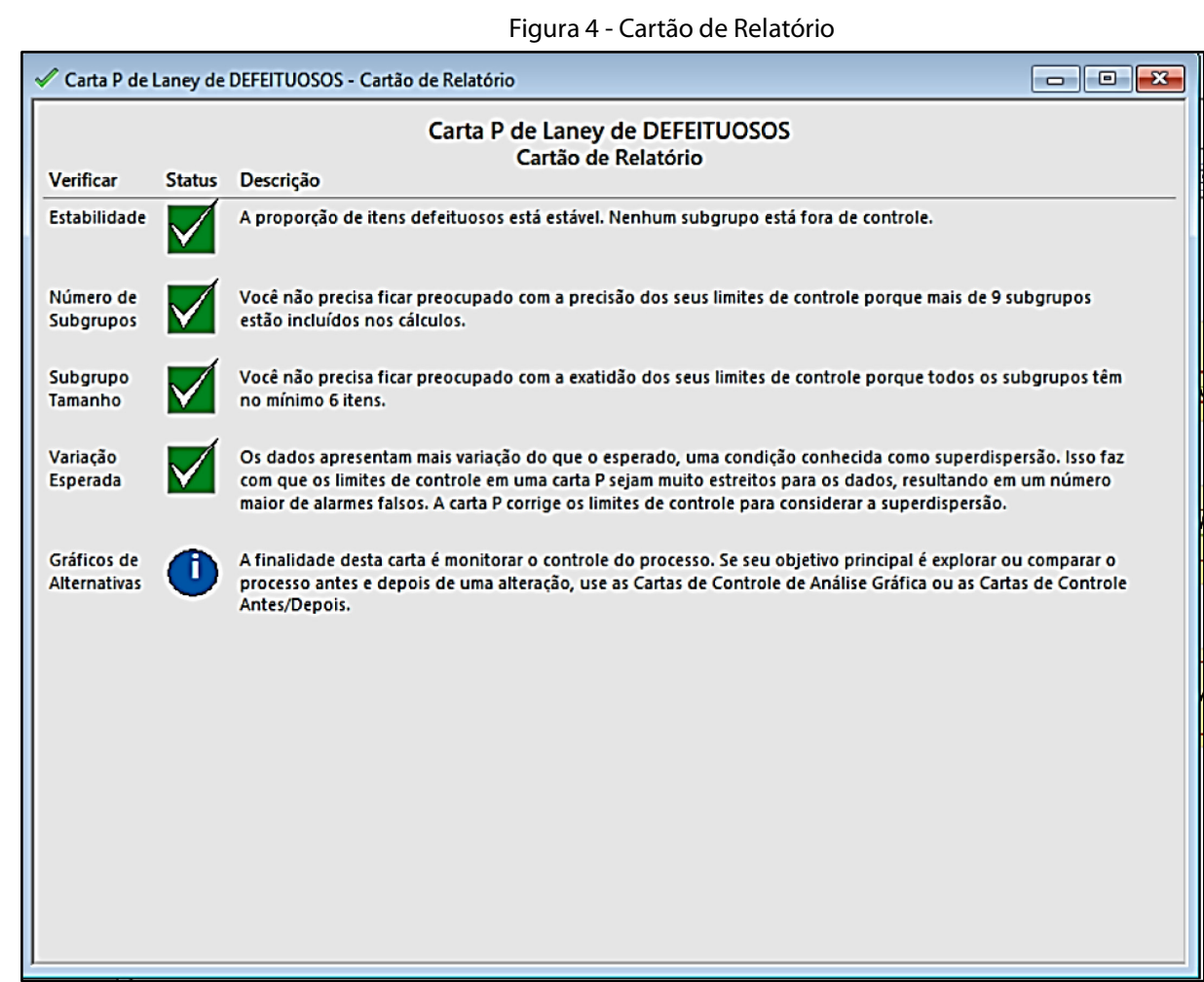

Fonte: Autores (2019)

Assim, para validação dos dados, o Minitab faz uma verificação de 3 indicadores que irão apontar se a amostra é válida ou não, os itens são: estabilidade; número de subgrupos; tamanho do subgrupo. Os outros 
dois itens que são exibidos na imagem acima são orientações feitas pelo software para confirmação da carta utilizada.

A validação da estabilidade do processo exibe que, na amostra, não há ocorrência de nenhuma causa especial, confirmando que os dados coletados podem representar a população. A validação do número de subgrupos e do tamanho da amostra é crucial para que os dados coletados possam vir a representar a população. Sendo assim, os dados foram autenticados para que se possa analisar a carta de controle.

\subsection{Análise da carta de controle}

Dentre os itens pontuados, no quadro 3 são exibidas fotos tiradas durante as amostragens, esses itens foram rotulados como defeituosos pela equipe de auditoria da qualidade da empresa. Na figura 05 é mostrado uma proporção média de itens defeituosos de $(\bar{p})$ 0,0883 ou $8,83 \%$.

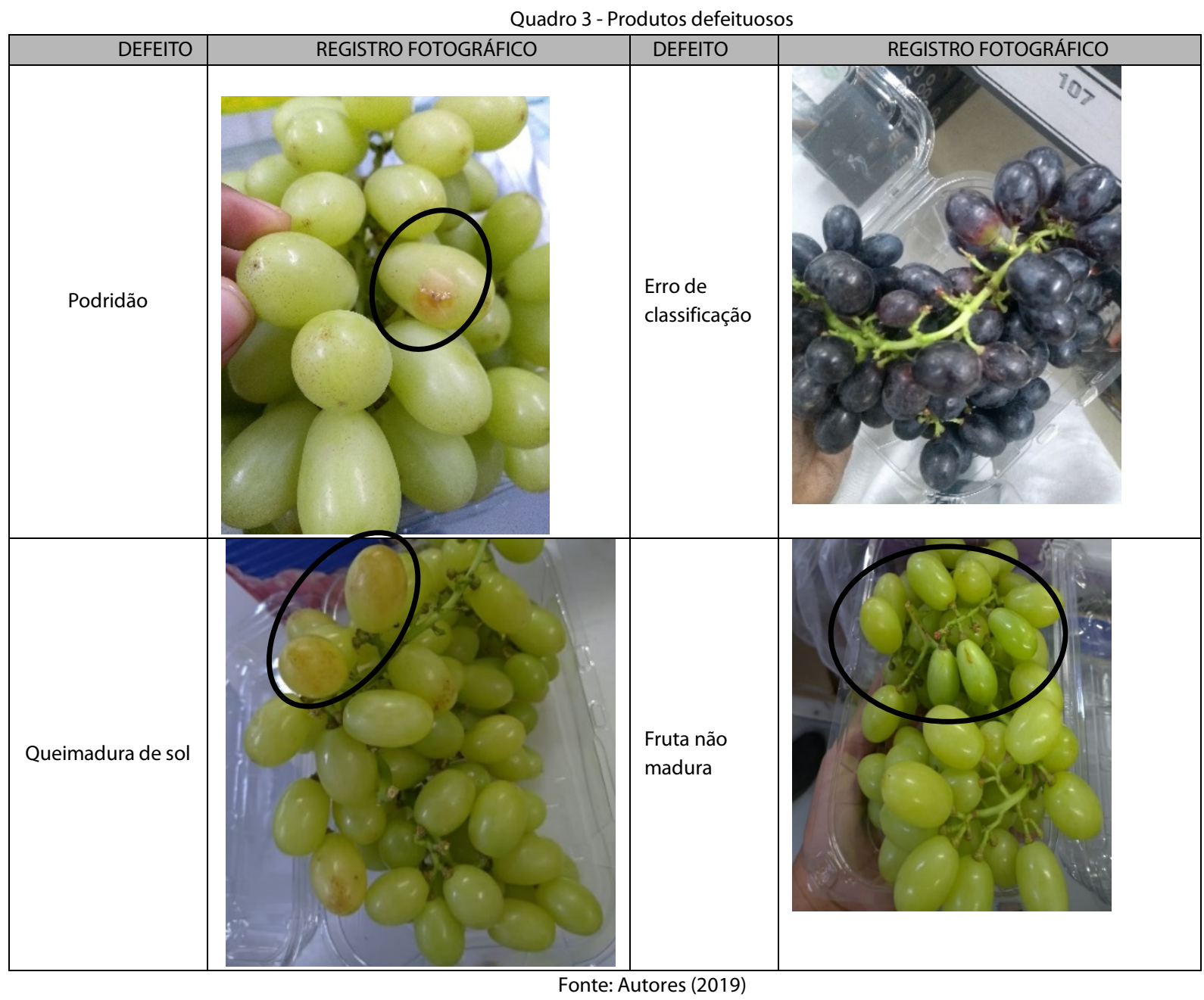

Dentre os 8,83\% dos itens pontuados como defeituosos, têm-se que 30,04\% foi reprovado por erro de classificação, onde o produto deveria estar em uma marca de qualidade inferior. Por sua vez, $25,75 \%$ foi devido a danos e cicatrizes, $20,55 \%$ foi devido a podridão no fruto, $19,28 \%$ foi devido a queimadura do sol na baga, 3,24\% é de peso baixo do produto e 1,14\% foi devido a presença de frutos não maduros.

Para a avaliação foram analisados 42 subgrupos (Figura 5), tendo cada subgrupo em média 505 caixas de $5 \mathrm{~kg}$, inspecionados. 
Figura 5 - Carta de Atributo P de Laney

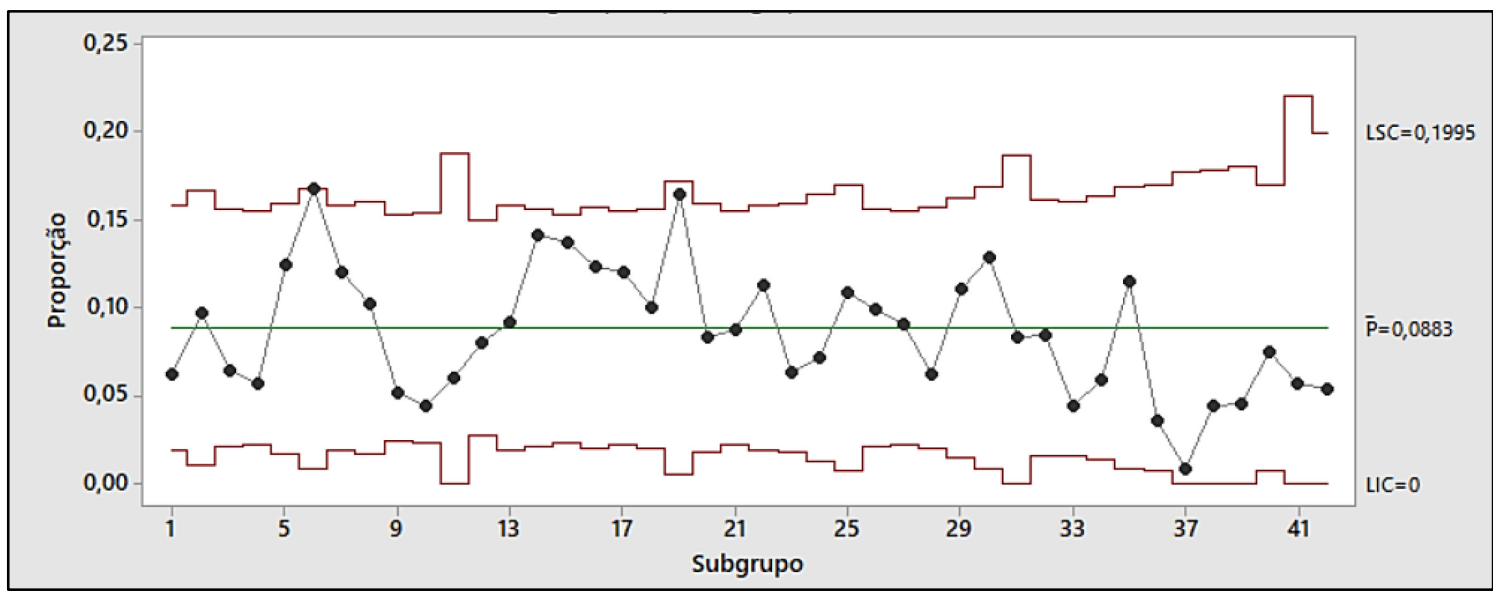

Fonte: Autores (2019).

$\mathrm{Na}$ carta de controle é nítido que entre os subgrupos 5 e 9 há um aumento no número de itens defeituosos. Em análise pode-se perceber que esse aumento foi ocasionado principalmente pelo aumento do índice de queimadura do sol nas frutas avaliadas.

Posteriormente, para obtenção da capacidade do processo de produzir itens conformes pode-se utilizar a equação (5) tendo um resultado de $91,17 \%$.

\subsection{Parecer sobre a empresa analisada}

Até a finalização da pesquisa, a empresa não tinha indicador gerencial que trata sobre controle da qualidade do processo de beneficiamento da uva de mesa no packing house. No início de 2019 a empresa estudada disponibilizou um relatório sobre o período analisado (outubro a dezembro de 2018), no qual a soma de devoluções e perdas pós-colheita somaram apenas $2,53 \%$ do faturamento líquido daquele momento. Sendo assim, o valor de 8,83\% foi satisfatório para o período de 2018. Entretanto, para o ano de 2019, a empresa traçou uma meta de $\bar{p} \leq 5 \%$ e acompanha esse indicador semanalmente com a equipe de beneficiamento da uva no packing house.

\section{CONCLUSÃO}

Esta pesquisa apresentou a aplicação da carta de controle por atributo $p$ no processo de beneficiamento de uva de mesa em um packing house. Foi constatado que o processo estava sobre controle estatístico e não havia ocorrência de causas especiais que gerassem inconformidades no processo de elaboração da carta.

Lima (2010) afirma que no packing house, a uva é submetida às operações e procedimentos que visam manter a sua qualidade por períodos compatíveis com a comercialização para mercados específicos. As etapas no packing house devem ser rápidas para que o tempo entre colheita e o resfriamento da fruta seja o menor possível.

A inspeção dos produtos acabados foi feita via checklist da equipe de qualidade e, em seguida, foi aplicado a carta de controle por atributo $p$ para a quantificação de itens defeituosos. A aplicação desses diversos gráficos para o monitoramento dos processos industriais e administrativos é de extrema importância para melhorar a produtividade e a lucratividade da empresa.

A empresa analisada, não possui registros de estudos realizados sobre o controle de itens defeituosos na etapa de beneficiamento. Foi obtida uma proporção média de itens defeituosos de 8,33\% nas avaliações feitas de outubro a dezembro de 2018. Desta forma, a empresa obteve um índice de capacidade de produção (C) de $91,17 \%$ em conformidade. Com os resultados obtidos a empresa traçou uma meta anual e passou a 
utilizar o indicador de capacidade de processo como indicador gerencial de acompanhamento semanal com o intuito de garantir a qualidade de seus produtos a seus clientes e consumidores.

\section{REFERÊNCIAS}

ANDRADE, M. G. de. Processo da irrigação localizada utilizando o controle estatístico de qualidade. 2016. 117 f. Tese (Doutorado) - Curso de Engenharia Agrícola, Centro de Ciências Exatas e Tecnológicas, Universidade Estadual do Oeste do Paraná, Cascavel, 2016.

ARAUJO, M. A.; LIMA, T. L. A.; SOBRAL, M. F. F. Gestão da informação: a adoção do BI por meio do uso dos sistemas ERP em Usinas Sucroalcooleiras. Revista Agropampa, v. 1, p. 78-92, 2019.

ASSOCIAÇÃO BRASILEIRA DE NORMAS TÉCNICAS. ISO 8402: Gestão da qualidade e garantia da qualidade: Terminologia. Rio de Janeiro, 1997.

ASSOCIAÇÃO BRASILEIRA DE NORMAS TÉCNICAS. NBR 5426: Planos de amostragem e procedimentos na inspeção por atributos. Rio de Janeiro: 1985.63 p.

BARBETTA, P.A. Estatística para cursos de engenharia e informática. São Paulo: Atlas, 2004. 410p.

BRAINER, M. S. DE C. P et al. A agroindústria de alimentos de frutas e hortaliças no nordeste e norte dos estados de minas gerais e espírito santo. In: CONGRESSO DA SOCIEDADE BRASILEIRA DE ECONOMIA, ADMINISTRAÇÃO E SOCIOLOGIA RURAL, 46., 2008, Rio Branco. Anais [....]. Rio Branco: Sober, 2008. p. 1 - 21. Disponível em: http://www.sober.org.br/palestra/9/639.pd. Acesso em: 10 fev. 2019.

BUAINAIN, A. M.; BATALHA, M. O. Cadeia produtiva de frutas. 7. ed. Brasília: IICA: MAPA/SPA, 2007.

CARVALHO, M. M. de; PALADINI, E. P. Gestão da qualidade: teoria e casos. 2. ed. São Paulo: Elsevier, 2012.

CENCI, S. A. (Ed.). Processamento mínimo de frutas e hortaliças: tecnologia, qualidade e sistemas de embalagem. 21. ed. Rio de Janeiro: Embrapa, 2011. 144 p.

CERVO, A. L.; BERVIAN, P. A.; SILVA, R. da. Metodologia científica. 6. ed. São Paulo: Pearson Prentice Hall, 2007.

CHOUDHURY, M. M. et al. Colheita e pós-colheita. In: LEÃO, P. C. de S. (Ed.). Uva de mesa: produção aspectos técnicos. Petrolina: Embrapa Semi-Árido, 2001. p. 106-111.

COSTA, H. T. S. da. Controle Estatístico de Processo aplicado a uma linha de produção de medicamento tópico de uma indústria farmacêutica. 2017. 164 f. Dissertação (Mestrado em Engenharia de Produção) Universidade Federal do Amazonas, Manaus, 2017.

CROSBY, P, B. Qualidade, falando sério. São Paulo: McGraw-Hill, 1990.

DOMINGUES, R. Ordenamento territorial, governança e a transposição de águas do São Francisco: uma perspectiva. Revista de Geografia e Ordenamento do Território, n. 8, p. 1-24, 2015.

JURAN, J. M. Juran on leadership for quality: an executive handbook. New York: Free Press, 1989.

LEÃO, Patrícia Coelho de Souza et al(Ed.). Cultivo da Videira. 1. ed. Brasília: Embrapa, Petrolina: 2004. Disponível em: https://ainfo.cnptia.embrapa.br/digital/bitstream/item/112196/1/Cultivo-da-videira32070.pdf. Acesso em: 12 fev. 2020. 
GIL, A. C. Como elaborar projetos de pesquisa. 5. ed. São Paulo: Atlas, 2008.

KIST, B B. Anuário Brasileiro da Fruticultura 2017. Santa Cruz do Sul: editora Gazeta Santa Cruz, 2017. Anual.

KIST, B B. Anuário Brasileiro da Fruticultura 2018. Santa Cruz do Sul: editora Gazeta Santa Cruz, 2018. Anual.

LIMA, M. A. C. de. Cultivo da Videira: Colheita e pós-colheita. 2010. Disponível em:

http://www.cpatsa.embrapa.br:8080/sistema_producao/spuva/colheita.html. Acesso em:07 mar. 2019.

LUENGO, R. F. A.; CALBO, A. G. Embalagens para comercialização de hortaliças e frutas. Brasília, DF, Embrapa Hortaliças. 2006. 7p. Manual Segurança e Qualidade para a Cultura de Uva de Mesa. Brasília: EMBRAPA/SEDE, 2004. 51 p. (Qualidade e Segurança dos Alimentos). Projeto PAS Campo. ConvênioCNI/SENAI/SEBRAE/EMBRAPA

MASCARENHAS, R. de J. et al. Qualidade sensorial e físico-química de uvas finas de mesa cultivadas no submédio São Francisco. Revista Brasileira de Fruticultura, v. 35, n. 2, p.546-554, 2013.

MELLO, L. M. R. de. Vitivinicultura brasileira: panorama 2015. Bento Gonçalves: Embrapa, 2016. 5 p.

MOTA, R. M. B.; FERNANDES, C. H. A.; SANTOS, A. A. R.; SANTOS, P. V. S. O Projeto Conceitual de um Produto Sustentável: Experiência Prática. Revista de Empreendedorismo e Inovação Sustentáveis - REVISE, v. 4, p. 62-74, 2019.

OLIVEIRA, M. F. de. Metodologia Científica: um manual para a realização de pesquisas em administração. 2011. 72 f. Monografia (Especialização) - Curso de Administração, Universidade Federal de Goiás, Catalão, 2011.

ORO, S. R. Aplicação de técnicas da engenharia da qualidade no aperfeiçoamento de um processo de produção na suinocultura. 2010. 91 f. Dissertação (Mestrado) - Curso de Métodos Numéricos em Engenharia, Construção Civil, Universidade Federal do Paraná, Curitiba, 2010.

GRAEML, A.R.;PEINADO, J. Administração da produção: operações industriais e de serviços. Curitiba: UnicenP, 2007.

PEREIRA NETO, A. R. Um estudo sistemático sobre o controle estatístico de processos e a definição de um catálogo de abordagens. 2018. 217 f. Dissertação (Mestrado) - Curso de Ciência da Computação, Instituto de Ciências Exatas e Naturais, Universidade Federal do Pará, Belém, 2018.

PRATA, D. F. R. F.; SANTOS, P. V. S. Qualidade em serviços de farmácias e drogarias segundo a percepção do cliente: um estudo de caso no Rio de Janeiro. Perspectivas Online: Humanas e Sociais Aplicadas, v. 27, p. 22-32, 2020. Doi: http://dx.doi.org/10.25242/8876102720201955

RIBEIRO, J. L. D.; TEN CATEN, C. S. Série monográfica Qualidade: Controle Estatístico do Processo. Porto Alegre: Feeng/UFRGS, 2012.

SAMOHYL, R. W. Controle Estatístico de Qualidade. Rio de Janeiro: Elsevier, 2009.

SANTOS, P. V. S. Aplicação do overall equipment effectiveness no sistema produtivo de uma vinícola. NAVUS - Revista de Gestão e Tecnologia, Florianópolis, v. 10, p. 01-14, 2020. Doi:

http://dx.doi.org/10.22279/navus.2020.v10.p01-14.933 
SANTOS, P. V. S.; SILVA, E. C. da. Gestão estratégica da qualidade aplicada à redução de devoluções. Navus Revista de Gestão e Tecnologia, Florianópolis, v. 9, n. 4, p. 30-48, 2019. Doi: https://doi.org/10.22279/navus.2019.v9n4.p30-48.884.

SANTOS, P. V. S. A introdução de tecnologias a favor da eficiência em operações logísticas: um estudo de caso no setor de serviços. Navus - Revista de Gestão e Tecnologia, Florianópolis, v. 9, n. 3, p. 55-68, 2019. Doi: https://doi.org/10.22279/navus.2019.v9n3.p55-68.819.

SANTOS, P. V. S. A Indústria Vinícola No Vale Do São Francisco e As Estratégias de Inserção No Mercado Nacional: Uma Revisão Bibliográfica. Future Studies Research Journal: Trends and Strategies, v. 9, n. 3, p. 39-68, 2017. doi:https://doi.org/10.24023/FutureJournal/2175-5825/2017.v9i3.317.

SELLTIZ, C.; WRIGHTSMAN, L. S.; COOK, S. W. Métodos de pesquisa das relações sociais. São Paulo: Herder, 1965.

VIDAL, M. F.; XIMENES, L. J. F. Comportamento recente da fruticultura nordestina: área, valor da produção e comercialização. Caderno Setorial ETENE, ano 1, n. 2, p. 18-26, out. 2016. Disponível em: https://www.bnb.gov.br/ . Acesso em: 24 mar. 2020.

VIEIRA, S. Estatística para a qualidade. 3. ed. Rio de Janeiro: Elsevier, 2014. 